Дуб М.М.

\title{
Характеристика захворюваності та поширеності хвороб ендокринної системи, розладів харчування та порушення обміну речовин у Закарпатській області
}

\author{
ДВНЗ «Ужгородський національний університет», м. Ужгород, Україна \\ marjana.dub@uzhnu.edu.ua
}

\begin{abstract}
Дуб М.М.
Характеристика заболеваемости

и распространенности болезней эндокринной

системы, расстройств питания и нарушения

обмена веществ в Закарпатской области

ГВУЗ «Ужгородский национальный университет», г. Ужгород, Украина
\end{abstract}

Dub M.M.

Characteristics of the incidence and prevalence of diseases of the endocrine system, eating disorders and metabolic disorders in the Transcarpathian region

"Uzhhorod National University", Uzhhorod, Ukraine

\section{Ветуі}

Надлишкова маса тіла та ожиріння за останні десятиріччя стали глобальною масштабною соціально значущою проблемою. Це зумовлено наслідками зростаючої поширеності ожиріння серед населення різних вікових груп у всіх країнах світу. За оцінками експертів, близько 1,7 млрд жителів нашої планети мають надлишкову вагу, а близько 300 млн потерпають від ожиріння. Згідно 3 даними ВООЗ кількість осіб, які страждають на ожиріння, за останні тридцять років збільшилася удвічі [1].

Відповідно до Європейської ініціативи ВООЗ організація безперервного систематизованого процесу виявлення осіб з надлишковою масою тіла та ожирінням, аналізу середовища, де знаходиться людина, 3 позиції соціальних характеристик та поведінкових особливостей $\epsilon$ важливим напрямком профілактики неінфекційних захворювань [2].

3 метою розробки ефективних заходів щодо профілактики поширення хвороб ендокринної системи, розладів харчування, порушення обміну речовин на рівні регіону слід проаналізувати стан та динаміку показників їх захворюваності та поширеності.

Мета - проаналізувати показники захворюваності та поширеності хвороб ендокринної системи, розладів харчування, порушення обміну речовин в Закарпатській області за 5-річний період.

\section{Матеріали та методи}

Матеріалом стали показники статистичних довідників «Мережа закладів та основні показники діяльності системи охорони здоров'я Закарпатської області» за 2014-2018 роки. Методи дослідження: системний аналіз, статистичний та графічний.

\section{Результати дослідження та їх обговорення}

В результаті аналізу показників (таблиця) встановлено, що протягом 2014-2018 років в Закарпатській області спостерігалося зростання захворюваності хвороб ендокринної системи, розладів харчування та порушення обміну речовин.

Так, у 2018 році показник поширеності хвороб ендокринної системи, розладів харчування, порушення обміну речовин $(11887,7$ на 100 тис. населення) в порівнянні з 2014 роком (11656,8 на 100 тис. населення) збільшився на $1,9 \%$. При цьому, найнижче значення показника в описаний період зафіксовано у 2014 році 11656,8 на 100 тис. населення. Найбільший приріст показника поширеності хвороб ендокринної системи, розладів харчування, порушення обміну речовин відмічений за період 2014-2016 рр. (рис. 1).

Виокремлені дані щодо вперше в житті зареєстрованих випадків із усіх зареєстрованих захворювань за класом «Хвороби ендокринної системи, розлади харчування, порушення обміну речовин» в Закарпатській області свідчать про зниження рівня захворюваності у 2018 році в порівнянні з 2014 роком на 17,9\%: 1430,2 та 1742,2 на 100 тис. населення відповідно. Зниження захворюваності, як можна стверджувати, відбувалося протягом вказаного періоду без різких коливань.

На діаграмі (рис. 1) чітко видно, що тенденції захворюваності та поширеності у 2014-2018 роках відрізняються. Так у 2014-2016 роках відмічається різкий ріст показника поширеності хвороб ендокринної системи, розладів харчування, порушення обміну речовин при зниженні загальних показників первинної захворюваності.

За обласними показниками динаміка реєстрації вперше виявлених захворювань не пов'язана з загальними 
тенденціями реєстрації захворювань хвороб ендокринної системи, розладів харчування, порушення обміну речовин.

Слід відмітити також, що вищі за обласні показники поширеності хвороб ендокринної системи, розладу харчування, порушення обміну речовин протягом 2014 2017 років відмічалися у м. Ужгород та окремих районах області: Ужгородському та Тячівському. Найнижчі показники поширеності хвороб ендокринної системи, розладів харчування, порушення обміну речовин спостерігались у Рахівському, Міжгірському та Перечинському районах.

Для детального аналізу показників захворюваності та поширеності хвороб ендокринної системи, розладу харчування, порушення обміну речовин в районах області проведено усереднення даних показників за 20142018 роки. Динаміку показників захворюваності та поширеності хвороб ендокринної системи, розладів харчування, порушення обміну речовин зображено на рис. 2.

Як бачимо на діаграмі (рис. 2) середні показники первинної захворюваності Великоберезнянського, Міжгірського та Рахівського районів перевищують значення обласного показника $(2377,4,2256,8$ та 2012,2 на 100 тис. населення проти 1601,7 на 100 тис. населення відповідно). На рівні обласного значення показник Воловецького району (1596,5 на 100 тис. населення).

Враховуючи вище наведені дані, можемо стверджувати, що на формування обласного показника захворюваності за класом хвороб ендокринної системи, розладами харчування, порушенням обміну речовин у 2014-2018 роках значною мірою вплинули надані закладами охорони здоров'я показники Великоберезнянського району.

Середній показник поширеності хвороб ендокринної системи, розладів харчування, порушенням обміну речовин перевищує обласне значення (11801 на 100 тис. населення) у м. Ужгороді $(14633,4)$, Ужгородському $(13318,2)$ та Тячівському районах $(12998,8)$. На рівні обласного значення показник Великоберезнянського району 11993,8 на 100 тис. населення. Найнижчий показник поширеності хвороб ендокринної системи, розладів харчування, порушенням обміну речовин в Рахівському та Міжгірському районах (7149 та 8240 на 100 тис. населення відповідно).

Таблиця. Хвороби ендокринної системи, розлади харчування, порушення обміну речовин у Закарпатській області (на 100 тис. населення)

\begin{tabular}{|c|c|c|c|c|c|c|c|c|c|c|}
\hline \multirow[t]{2}{*}{$\begin{array}{l}\text { Адміністративно- } \\
\text { територіальна } \\
\text { одиниця }\end{array}$} & \multicolumn{5}{|c|}{$\begin{array}{c}\text { Заресстровано захворювань ендокринннної } \\
\text { системи, розладів харчування, порушення } \\
\text { обміну речовин (Е00-Е90) }\end{array}$} & \multicolumn{5}{|c|}{$\begin{array}{c}\text { В т.ч. вперше в житті заресстровано } \\
\text { захворювань ендокринної системи, } \\
\text { розладів харчування, порушення обміну } \\
\text { речовин (Е00-Е90) }\end{array}$} \\
\hline & 2014 & 2015 & 2016 & 2017 & 2018 & 2014 & 2015 & 2016 & 2017 & 2018 \\
\hline $\begin{array}{l}\text { Берег } \\
\text { район }\end{array}$ & 1 & 132 & 6 & 1 & 2 & 1463,9 & , 0 & , 0 & 1 & 196 \\
\hline $\begin{array}{l}\text { Великоберезнян- } \\
\text { ський район }\end{array}$ & 0 & 1157 & 121 & 122 & 129 & 2538,3 & 2650,6 & , 0 & 2063,7 & 2302,6 \\
\hline $\begin{array}{l}\text { Виноградівський } \\
\text { район }\end{array}$ & 7 & 1121 & 1 & 11755,8 & 7 & 1916,2 & 1323,0 & 4 & 1957,5 & 1684,6 \\
\hline $\begin{array}{l}\text { Воловецький } \\
\text { район }\end{array}$ & 12506,6 & 12286,4 & 12894,9 & 12333,6 & 12333,6 & 1902,7 & 1705,0 & 1960,2 & 1226,9 & 1187,7 \\
\hline Іршавський район & 12192,4 & 12178,2 & 12640,0 & 13035,0 & 12936,6 & 2329,1 & 1771,3 & 1847,8 & 1785,9 & 1571,4 \\
\hline $\begin{array}{l}\text { Міжгірський } \\
\text { район }\end{array}$ & 7505,0 & 7359,1 & 7968,4 & 8729,4 & 8,4 & 2389,7 & 1815,3 & 2444,9 & 2323,6 & 2310,3 \\
\hline $\begin{array}{l}\text { Мукачівський } \\
\text { район }\end{array}$ & 53,0 & 10246,0 & 10226,3 & 10085,4 & 9 & 1106,9 & 1223,7 & 1031,6 & 942,4 & 908,8 \\
\hline $\begin{array}{l}\text { Перечинський } \\
\text { район }\end{array}$ & 10153,6 & 9967,2 & 729,9 & 8,9 & 9283,7 & 2191,2 & 2112,0 & & 1832,5 & 1710,8 \\
\hline Рахівський район & 9062,3 & 8840,9 & 8691,8 & 8371,1 & 778,9 & 2547,3 & 2274,0 & 1923,7 & 1822,3 & 1493,8 \\
\hline $\begin{array}{l}\text { Свалявський } \\
\text { район }\end{array}$ & 11168,3 & 11321,2 & 11325,5 & 11622,5 & 11795,5 & 1692,3 & 1748,1 & 1438,2 & 1472,5 & 1414,1 \\
\hline Тячівський ра & 12841,6 & 12662,1 & 12970,0 & 13166,7 & 13353,4 & 1475,0 & 1400,6 & 1474,0 & 1356,5 & 1406,4 \\
\hline $\begin{array}{l}\text { Ужгородський } \\
\text { район }\end{array}$ & 12011,5 & 12591,0 & 14312,8 & 13408,6 & 14267,2 & 1821,6 & 2105,4 & 1911,0 & 1706,2 & 1829,6 \\
\hline Хустський район & 11816,7 & 11824,5 & 12344,5 & 12852,3 & 13090,3 & 1661,0 & 1609,2 & 1728,6 & 1787,9 & 1645,6 \\
\hline м. Ужгород & 15825,2 & 14951,7 & 14462,6 & 14069,7 & 13857,7 & 1466,1 & 1389,1 & 1280,8 & 1188,1 & 1089,5 \\
\hline $\begin{array}{l}\text { Закарпатськ: } \\
\text { область }\end{array}$ & 11656,8 & 11736,7 & 11864,8 & 11859,1 & 11887,7 & 1742,2 & 1682,5 & 1622,9 & 1530,6 & 1430,2 \\
\hline
\end{tabular}







порушенкя обмміну речовин в Закарпатськіґ об̆ласті (2014-2018 роки), на 100 тис. населенкя.

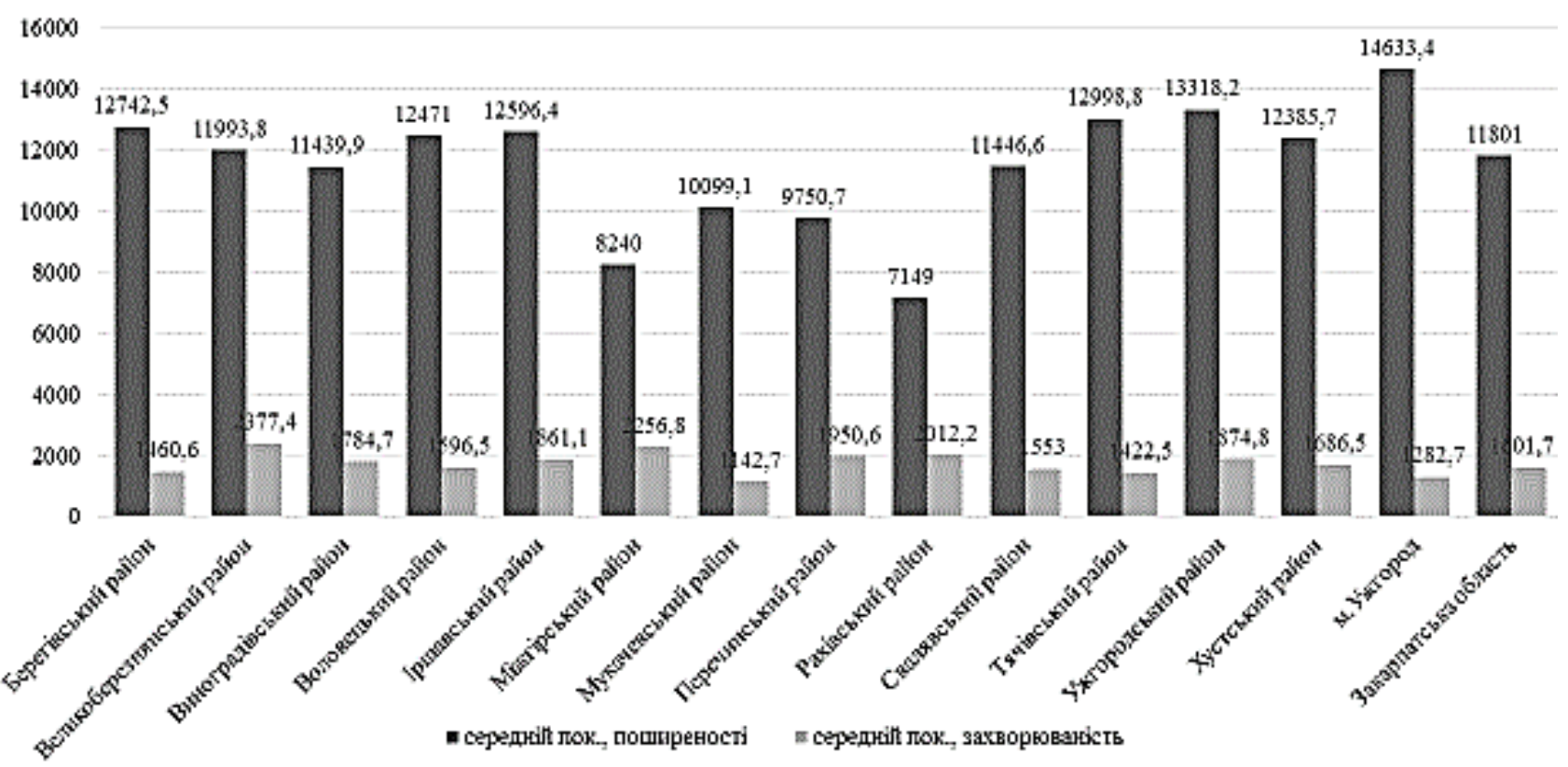

Рис. 2. Порівняння середніх показнгків первннної та загатьної захворюваності хворобами ендокрнгної системп, розладампи

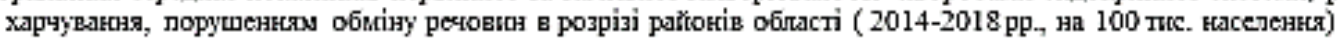

Отже, враховуючи вище викладене, можемо стверджувати, що на формування обласного показника хвороб ендокринної системи, розладів харчування, порушенням обміну речовин у 2014-2018 роках значною мірою вплинули показники м. Ужгорода та Ужгородського району. Середній показник поширеності в м. Ужгороді перевищує середній показник по області на $19,4 \%$, проте показник захворюваності від обласного показника на $80 \% \in$ нижчим. Щорічне перевищення районного над обласним показником спостерігається і в
Ужгородському районі, середній показник поширеності у вказаному районі перевищує обласний на 11,4 \%.

На підставі аналізу даних щодо показників захворюваності та поширеності хвороб ендокринної системи, розладів харчування, порушення обміну речовин у 2014-2018 роках у розрізі районів області із застосуванням методу усереднення можна прийти до висновку, що в більшості районів області динаміка реєстрації вперше виявлених захворювань хвороб ендокринної системи, розладів харчування та порушення 
обміну речовин пов'язана 3 загальними тенденціями реєстрації цих нозологій.

Перспективи подальших досліджень полягають у подальшому вивченні показників захворюваності та поширеності хвороб ендокринної системи, розладів харчування, порушень обміну речовин.

\section{Висновки}

В результаті проведеного аналізу можна зробити наступні висновки:

1. Встановлено, що у 2018 році в порівнянні 3 2014 роком в Закарпатській області спостерігалося збільшення рівня поширеності хвороб ендокринної системи, розладів харчування, порушення обміну речовин на 1,9\%, та зниження рівня захворюваності на $17,9 \%$.

2. Визначено, що за обласними показниками динаміка реєстрації вперше виявлених захворювань за класом Е00-Е90 не пов'язана 3 загальними тенденціями реєстрації цих захворювань.

3. Виявлено, що на формування обласного показника поширеності у 2014-2018 роках значною мірою вплинули показники м. Ужгород та Ужгородського району.

4. Отримані результати аналізу захворюваності та поширеності хвороб ендокринної системи, розладів харчування, порушення обміну речовин потребують додаткового детального вивчення за районами та окремими нозологіями.

\section{Лiтература}

1. World Health Organization, Regional Office for Europe [Електронний ресурс]. - Режим доступу: http://www.who.int/mediacentre/factsheets/fs311/en/.

2. Childhood Obesity Surveillance Initiative (COSI), Protocol October 2016. WHO Regional Office for Europe, Geneva, World Health Organization, 2017. - 23 р. [Електронний ресурс]. - Режим доступу: http://www.euro.who.int/data/assets/ pdf_file/0018/333900/COSI-protocol-en.pdf.

3. Заклади охорони здоров'я та захворюваність населення України у 2016 році: статистичний збірник. URL: http://www.ukrstar.gov.uadruk/publicat/kat_u/2016/bl/06/bl_zoz 15xl.zip.

4. Заклади охорони здоров'я та захворюваність населення України у 2017 році: статистичний збірник. URL: http://www.ukrstar.gov.uadruk/publicat/kat_u/2017/bl/06/bl_zoz 15xl.zip.

\section{References}

1. World Health Organization, Regional Office for Europe. - http://www.who.int/mediacentre/factsheets/fs311/en/.

2. Childhood Obesity Surveillance Initiative (COSI), Protocol October 2016. WHO Regional Office for Europe, Geneva, World Health Organization, 2017. - 23 p. - http://www.euro.who.int/data/assets/ pdf_file/0018/333900/COSI-protocol-en.pdf.

3. Zaklady okhorony zdorov"ya ta zakhvoryuvanist' naselennya Ukrayiny u 2016 rotsi: statystychnyy zbirnyk. URL: http://www.ukrstar.gov.uadruk/publicat/kat_u/2016/bl/06/bl_zoz 15xl.zip.

4. Zaklady okhorony zdorov"ya ta zakhvoryuvanist' naselennya Ukrayiny u 2017 rotsi: statystychnyy zbirnyk. URL: http://www.ukrstar.gov.uadruk/publicat/kat_u/2017/bl/06/bl_zoz 15xl.zip.

Дата надходження рукопису до редакції: 16.06.2020 p.

Мета: проаналізувати показники захворюваності та поширеності хвороб ендокринної системи, розладів харчування, порушення обміну речовин у Закарпатській області за 5-річний період (2014-2018рp.).

Матеріали та методи. Матеріалами стали показники статистичних довідників «Мережа закладів та основні показники діяльності системи охорони здоров’я Закарпатської області» за 2014-2018 роки. Методи: системного аналізу, статистичний та графічний методи.

Результати. Встановлено, що у 2018 році в порівнянні з 2014 роком в Закарпатській області спостерігалося збільшення рівня поширеності хвороб ендокринної системи, розладів харчування, порушення обміну речовин на 1,9\%, та зниження рівня захворюваності на 17,9\%. Визначено, що за обласними показниками динаміка реєстрації вперше виявлених захворювань за класом Е00-Е90 не пов'язана з загальними тенденціями реєстрації цих захворювань.

Висновки. Рівні захворюваності та поширеності хвороб ендокринної системи, розладів харчування та порушення обміну речовин у Закарпатській області мають тенденцію до збільшення рівня поширеності та потребують додаткового детального вивчення за районами та окремими нозологіями.

Ключові слова: захворюваність, поширеність, ендокринна система, харчування, обмін речовин.

Цель: проанализировать показатели заболеваемости и распространенности болезней эндокринной системы, расстройства питания, нарушения обмена веществ в Закарпатской области за 5-летний период (2014-2018 гг.). 
Материалы и методы. Материалами стали показатели статистических справочников «Сеть заведений и основные показатели деятельности системы здравоохранения Закарпатской области» по 2014-2018 годы. Методы: системного анализа, статистический и графический методы.

Результаты. Установлено, что в 2018 году по сравнению с 2014 годом в Закарпатской области наблюдалось увеличение уровня распространенности болезней эндокринной системы, расстройств питания, нарушения обмена веществ на 1,9\%, и снижение уровня заболеваемости на $17,9 \%$. Определено, что за областными показателями динамика регистрации впервые выявленных заболеваний по классу Е00-Е90 не связана с общими тенденциями регистрации этих заболеваний.

Выводы. Уровни заболеваемости и распространенности болезней эндокринной системы, расстройства питания и нарушения обмена веществ в Закарпатской области имеют тенденцию к увеличению уровня распространенности и требуют дополнительного детального изучения по районам и отдельным нозологиям.

Ключевые слова: заболеваемость, распространенность, эндокринная система, питание, обмен веществ.

Objective: to analyze the incidence and prevalence of diseases of the endocrine system, eating disorders, metabolic disorders in the Transcarpathian region for a 5-year period (2014-2018).

Materials and methods. The materials were the indicators of statistical directories "Network of institutions and the main indicators of the health care system of the Transcarpathian region" for 2014-2018. Methods: system analysis, statistical and graphical methods.

Results. It is established that in 2018 compared to 2014 in the Transcarpathian region there was an increase in the prevalence of diseases of the endocrine system, eating disorders, metabolic disorders by $1.9 \%$, and a decrease in morbidity by $17.9 \%$. It is determined that according to regional indicators, the dynamics of registration of newly detected diseases in the class E00-E90 is not related to the general trends in the registration of these diseases.

Conclusions. The incidence and prevalence of diseases of the endocrine system, eating disorders and metabolic disorders in the Transcarpathian region tend to increase the prevalence and require additional detailed study by district and individual nosologies.

Key words: morbidity, prevalence, endocrine system, nutrition, metabolism.

\section{Відомості про автора}

Дуб Мар'яна Михайлівна - магістр громадського здоров’я, ст. викладач кафедри наук про здоров’я факультету здоров’я та фізичного виховання, ДВНЗ «Ужгородський національний університет»; вул. Митна, 29, м. Ужгород, Закарпатська обл., 88000, Україна.

marjana.dub@uzhnu.edu.ua. 